\title{
Forderungen an die Stromversorgung für die Halbleiterindustrie
}

\author{
T. Reisinger
}

Online publiziert am 20. November 2017

(c) Springer-Verlag GmbH Austria, ein Teil von Springer Nature 2017

Eine stabile und verlässliche Stromversorgung ist für die Halbleiterindustrie ein zentraler Faktor, um wettbewerbsfähig zu sein, denn die investitionsintensiven, hochsensiblen Anlagen sind bei Infineon Austria 365 Tage im Jahr im Vollschichtbetrieb ausgelastet. Daher hat der Stromlieferant die wesentliche Aufgabe, eine sichere Versorgung der benötigten Leistung und darüber hinaus eine hohe Stabilität und Qualität der Versorgungsspannung zur Verfügung zu stellen; denn Störungen in der Stromversorgung ziehen unmittelbar Kosten für Material und Ersatzteile nach sich. Damit einhergehend sind entsprechende Umsatzeinbußen verbunden, denn Prozessabbrüche bzw. Prozessschwankungen führen zum Verwurf der Produkte, die sich im Produktionsprozess befinden. Schwankungen im 100-Millisekunden-Bereich bringen direkt - oder über Infrastrukturausfall indirekt - Teile der Produktion zum Stillstand.

Weitere Anforderungen betreffen die unterbrechungsfreie Stromversorgung bei Erweiterungen, Wartungen und Störungsbehebun- gen im Stromnetz sowie ein störungs- und fehlerfreies Zusammenspiel aller Netzarten intern (Normalnetz, unterbrechungsfreie Stromversorgung [USV], Notstromversorgung). Treten Spannungseinbrüche auf, bilden vor allem eine rasche Kommunikation und gute Zusammenarbeit mit dem Netzbetreiber ein wichtiges Kriterium, um Vorfälle in der Fertigung genau zu analysieren und zeitnah entsprechende Maßnahmen zu setzen. Die Häufigkeit der Instabilitäten im Stromnetz mit großen Auswirkungen auf unsere Fertigung hat in den letzten Jahren signifikant zugenommen. Daher liegt der Fokus darauf, gemeinsam technische Lösungen zu entwickeln, die die Schwankungen des Netzes abpuffern. Ziel ist eine reibungslose, unterbrechungsfreie Produktion als zentraler Wettbewerbsfaktor und Grundlage für eine nachhaltige Standortabsicherung.
Kurzfassung eines Vortrags bei der 55. Fachtagung der Österreichischen Gesellschaft für Energietechnik (OGE) im OVE, die am 12. und 13. Oktober 2017 in Salzburg stattfand.

Reisinger, Thomas, Infineon Technologies Austria AG, Siemensstraße 2, 9500 Villach, Österreich (E-Mail: Thomas.Reisinger@infineon.com) 